\title{
COVID-19: LECCIONES APRENDIDAS Y ORIENTACIONES FUTURAS.
}

José Luis Recalde ${ }^{1 *}$

DOI: 10.48018/rmv.v31.i2.1

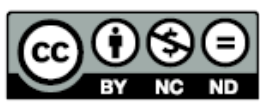

Este artículo está bajo una licencia de Creative Commons de tipo Reconocimien- No como Reconocimien- No comercial - Sin obras OPEN ACCESS

1 Hospital Vozandes Quito SA. Subdirección Médica. Quito - Ecuador

ORCID ID:

José Luis Recalde:

orcid.org/0000-0002-1661-7086

*Corresponding author: José Luis Recalde

E-mail: jrecalde@hospitalvozandes.com

Article history

Accepted: 15- dec - 2020

Publish: 31- dec - 2020

Conflict of interest: All authors declared that there are no conflicts of interest

Financial disclosure: The authors have no financial relationships relevant to this article to disclose

Forma de citar este artículo:

Recalde JL. COVID-19: LECCIONES APRENDIDAS Y ORIENTACIONES

FUTURAS. Rev Med Vozandes. 2020; 31 (2): 9 - 10
La pandemia ha ocupado, desde hace ya casi un año, la atención de la sociedad de manera abrumadora y constante. Antes de la declaratoria oficial en marzo de 2020, la creciente expectativa por lo que ocurría al otro lado del mundo, preocupó inicialmente a la comunidad científica y luego, al igual que los contagios de la enfermedad, alcanzó proporciones mundiales.

Concretamente en Ecuador, dada la distancia geográfica con la ciudad de Hubei en la provincia de Wuhan en China, la perspectiva de una situación catastrófica fue impensable y por lo tanto impensada. Esto, a pesar de que la opinión de muchos coincida, acerca de que ningún sistema de salud pudo estar preparado para enfrentar la crisis, fue determinante en los eventos que ocurrieron, de manera precipitada, pocas semanas después del reporte y confirmación del primer caso sospechoso el 29 de febrero de 2020. El tiempo transcurrido entre este suceso puntual y la transmisión comunitaria de la enfermedad, fue tan corto como turbulento de tal forma que, apenas, 9 meses más tarde podemos echar una mirada hacia atrás y hacer la necesaria reflexión sobre lo ocurrido.

¿Qué hemos aprendido y qué nos falta por aprender?, ¿̇ué hemos aprendido como sociedad, como profesionales de la salud y como individuos? Sin duda, tenemos más preguntas que respuestas. Seguramente las respuestas vendrán con el tiempo. En el ámbito científico - académico, afortunadamente. hemos sido testigos de una incesante búsqueda, tal vez a un ritmo nunca visto, este fenómeno, claramente ejemplificado en la carrera por obtener una vacuna que cumpla con los ideales de eficacia y universalidad, indispensables para superar la pandemia.

Lo que sabemos es relativamente poco, pero, es la base de lo que hemos ganado: los virus son agentes cuyo objetivo parece ser igual al de otros seres vivos, hacer perdurar su material genético. Esto, desde la perspectiva de la vida es lógico y natural, sin embargo, al ser agentes patológicos, el impacto que tienen sobre nuestra especie es determinante. En general podemos decir que, para que un virus genere como resultado de su proceso vital, una pandemia, debe tener un alto índice de transmisibilidad y un bajo grado de virulencia, de tal manera que no todos los infectados perezcan y su propagación pueda continuar.

A ciencia cierta, también sabemos que, el comportamiento gregario de los humanos, la llamada sociedad de consumo y la globalización, finalmente generan el escenario perfecto para ciertos patógenos que cumplen con las cualidades mencionadas. Comparativamente, menos regiones del planeta fueron afectadas por la pandemia de influenza de 1918 que por la actual, precisamente por la menor cantidad de intercambios comerciales, incluido el turismo considerado como tal.

De la misma manera, hemos aprendido que los medios de comunicación jugaron un rol preponderante en la difusión de la información, pero también de la desinformación. En muchos casos, se convirtieron en voceros oficiales, lamentablemente, sin observar todo el tiempo la ética profesional, generando ansiedad y un alto riesgo de impacto negativo en la salud mental de la población. 
Las economías fuertes tampoco estuvieron preparadas, lo cual puede ser un indicio de que, no importa el desarrollo económico sino, cuánto del presupuesto se asigna, de manera efectiva a los gastos en salud y de cómo esos recursos se utilizan eficientemente. Aún así, países con políticas muy apropiadas en términos de salud pública, sufrieron los embates de la pandemia casi con igual rigor que otros menos previsores. Sin embargo, en muchos casos particulares, se rescata los esfuerzos, no esporádicos, por hacer más ágiles los procesos de gestión para adquirir insumos indispensables e incluso, modificar la infraestructura y ampliar la capacidad instalada.

Otra arista, es el aspecto bioético el cual, durante esta pandemia, ha alcanzado todos los resquicios de la relación médico - paciente convirtiéndose en un tema de gran actualidad, principalmente, en su rol de garante de decisiones anticipadas, la correcta utilización de los recursos y el deber de cuidado sobre elriesgo de contagio. En nuestro ámbito social, cuyo enfoque muy particular de lo que consideramos respeto a la vida, estos detalles tienen una relevancia extrema. En este punto, nos falta mucho por contagiados y los "gadgets", avanzar tanto en legislación como complementos de los anteriores, en deontología, serán necesarios más allá de la novedad, deben los espacios de diálogo que pueda ser elementos que lleguen y se generar la sociedad para reflexionar perfecciones, ojalá, para quedarse. sobre estos temas.

La vigilancia epidemiológica, otro aspecto de actualidad que, en el pasado, recibió el tratamiento de hermana menor en la salud pública, se ha consolidado como el hilo conductor y marcapasos de la pandemia. Se resaltan los esfuerzos de cada profesional sanitario cuyo silencioso trabajo aporta los datos necesarios para la investigación y el análisis.

Finalmente, latecnología, indispensable en tiempos de pandemia, a través de múltiples herramientas tanto de uso común como de uso estrictamente médico, ha contribuido, en muchos casos a enfrentar los desafíos que se han encarado las personas, familias y comunidades. En el plano personal, tener la posibilidad de conectarse con familiares y amigos durante los períodos de confinamiento, fue un factor decisivo en la salud mental y la tan de moda, resiliencia. La telemedicina, los aplicativos para determinar la proximidad de posibles
El futuro debe estar marcado por la esperanza, la esperanza a su vez, por las aspiraciones de la sociedad; que los aprendizajes trasciendan la comunidad científica y nutran el conocimiento de la humanidad, el tan ansiado sentido común que facilite la convivencia y mejore la calidad de vida. Que la vacuna no sea un bien que reciba un tratamiento similar al que recibieron los elementos del equipo de protección personal al inicio de la pandemia con una artificial e intencionada escasez y el consecuente alto costo, privativo para ciertos sectores y países.

En conclusión, para cualquier forma de vida la crisis genera cambios y los cambios aprendizajes cuyo único fin, es la adaptación y la supervivencia, en nuestro caso, el significado que le otorgamos a la crisis depende de nuestra manera de ver la realidad, podemos seguir preguntándonos por qué ha ocurrido todo esto o podemos elegir preguntarnos qué haremos de ahora en adelante. 